\title{
How to restore public trust in science
}

The relationship between the scientific community and the general public has never been worse in living memory. The commercialization of research is largely responsible, but scientists can still act on the problem.

\section{Benny Haerlin and Doug Parr}

The scientific community has a credibility problem. In a recent survey, for example, $26 \%$ of European citizens named environmental organizations when asked whom they trusted most to tell the truth about genetically modified (GM) crops ${ }^{1}$. Only $6 \%$ named universities, $4 \%$ national public authorities and $1 \%$ industry.

Such dwindling credibility of scientific institutions has been attributed to the disaster over bovine spongiform encephalopathy. But previous events had followed similar patterns: the debate about CFCs and the ozone hole in the 1980s, for example, the health and environmental assessment of toxic substances, global warming, and even smoking. The role of corporate scientists in these cases has not been admirable, and the attitude of industry and scientific institutions, in demanding conclusive proof to justify preventative action, has rightly not reassured the public about scientists' trustworthiness.

Such experiences led to the development of the 'precautionary principle' by legislators around the world to shift the burden of proof from protectors to perpetrators. It is unfortunate that many use 'sound science' as a battle cry against this principle, and erroneously dismiss environmental and ethical concerns as 'anti-scientific'.

Sound science is about the best possible way to answer a given question; to present with rigour the certainties and uncertainties of knowledge, and the assumptions underlying certain conclusions. But, crucially, it is not a method for deciding which questions should be posed, or for determining the acceptable risks and desirable benefits of technologies.

There are no clear answers to many of the 'big picture' scientific questions asked by the public, in many cases because we lack the knowledge, but in others because arbitration between different answers is beyond scientific competence. When asked about impacts on diversity and evolution, the shape of future agricultural landscapes, and the changing perception of food and health, honest scientists will frequently have to answer: 'We don't know', 'We cannot know' or 'These are our guesses'. Such honest answers could help a great deal to raise credibility and to return the responsibility for decision-making from corporate interests to its rightful place: public bodies.

Arguing that science is the sole arbiter of policy action undermines trust in the concept of scientific analysis. The main culprits in the devaluing of scientific authority are not nec-
Codes of conduct should be extended to make companies and scientists communicate information on environmental and health impacts of products

essarily scientists themselves but corporations and politicians, keen to rely on the illusory picture of authoritative scientific arbitrators. Scientists are no longer perceived exclusively as guardians of objective truth, but also as smart promoters of their own interests in a media-driven marketplace.

This changing role can be seen in molecular biology, where the line between fundamental science and applied technology appears particularly thin, and where corporate funding has become the driving force of research. Privatization of science has become official policy in all industrialized nations since the early 1980s. Not only has public spending on research in Europe, particularly in biology and agriculture, been dwindling over the past decade but, as Richard Strohman bluntly observed, "academic biologists and corporate researchers have become indistinguishable, and special awards are given for collaborations between these two sectors for behaviour that used to be cited as a conflict of interest"2.

Integration of academic research into the market, however innovative, demands a price on the role and credibility of scientists. Critics should first address governments that believe that the market should be their prime adviser on science policy. Not only is it unfair to blame scientists for losing their independence, but it stifles an urgently needed open and honest dialogue between scientists and the public.

One prerequisite for such a dialogue might be a reliable scheme of transparency on patents, financial interests and corporate affiliations. The first laudable steps being taken by journals and public authorities must lead to clear rules that can be checked by the public. Codes of conduct should be extended to compel companies and institutions to communicate information on environmental and health impacts of products, and to oblige individual scientists to communicate relevant findings. Such an analogy to the Hippocratic oath would strengthen the position and responsibility of scientists within corporate and institutional systems.
Beyond scientific independence and conflicts of interest, worries stem from an explosive increase in available data and specialization, and the likelihood is of increasing fragmentation of scientific knowledge and perception. Failures of science to predict negative outcomes seem to arise when a reductionist method encounters situations of high complexity. Interdisciplinary and holistic understanding about highly complex issues will not come from individual scientists, but will require entirely new and innovative approaches.

Who cares about this 'big picture', and who is responsible for the integration of knowledge? Corporations see little use in investing in integrated scientific concepts: their integrating forces are product development and marketing. Where are the scientific authorities and the editorials in journals challenging public and corporate research strategies and perspectives? Where are the scientific authorities to insist that the identification and patenting of individual genes of interest are not good enough to develop sound scientific understanding? Who dares to say that further specialization is a recipe for disasters?

Inevitably, the framing of these questions is affected by value judgements. The UK Royal Commission on Environmental Pollution advises that decisions on environmental issues "must be informed by an understanding of people's values", and that "The public should be involved in the formulation of strategies, rather than merely being consulted on drafted proposals." 3

In the case of genetically engineered crops, surveys in Europe have consistently shown broad rejection of GM food. The governmental and corporate reaction has been to spend millions to 'educate' people about the perceived benefits of an 'inevitable' technology. The result has been greater understanding of the technology combined with firmer rejection of it. Instead of rethinking their research and develoment strategies and looking at the alternatives, most companies and governments still treat public acceptance as just an additional challenge to be overcome by asserting the safety of the technology. They are out of touch with the values of society, and that cannot be overcome by means of any scientific risk assessment. Benny Haerlin is at Greenpeace International, Chausseestrasse 131, D-10115 Berlin, Germany. Doug Parr is at Greenpeace UK, Canonbury Villas, London N1 2PN, UK.

\footnotetext{
1. European Commission DG XII Eurobarometer 46.1, 77-78 (1997). Strohman, R. Nature Biotechnol. 15, 194-200 (1997).

3. Royal Commission on Environmental Pollution Settin Environmental Standards (HMSO, London, 1998).
} 